$15^{\text {th }}$ International Conference on

AEROSPACE SCIENCES \& AVIATION TECHNOLOGY,

ASAT - 15 - May 28 - 30, 2013, Email: asat@mtc.edu.eg,

Military Technical College, Kobry Elkobbah, Cairo, Egypt,

Tel: +(202) $24025292-24036138$, Fax: +(202) 22621908

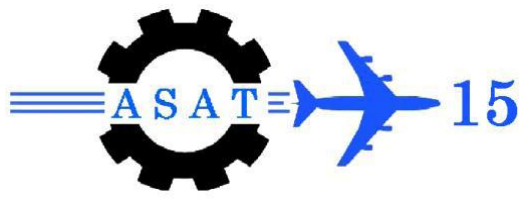

\title{
Development of a Wireless Testing System for Automotive Multistage Mechanical Transmissions; a Smart Diagnostic System for Condition Based Maintenance
}

\author{
$\left\{\text { H. Mohamed }{ }^{*}, \text { A. Onsy }{ }^{\dagger}, \text { W. M. Hussein }{ }^{*} \text { and I. A. El Sherif }\right\}^{\S * *}$
}

\begin{abstract}
Power transmissions are one of the most important parts of any mechanical system. In order to achieve the reliable operation of these systems, effective maintenance strategies must be used. Predictive health monitoring (PHM) and condition based maintenance (CBM) strategies are currently gaining in popularity due to their effectiveness in reducing maintenance costs; however, these require reliable monitoring techniques such as vibration analysis, acoustic emission, oil debris analysis and thermal analysis. This paper different monitoring features have been studied in order to develop an online monitoring tool that able to track the condition of an operating transmission system, classifying faults, and detect the onset of failure. The study presents an online PHM system utilising autoregressive (AR) parametric method algorithms based on vibration data. The online monitoring algorithm can support CBM and PHM of automotive multistage manual transmissions. The design, operation and validation of the online system are described and demonstrated. The results of the experimental test prove the system's capability and support the recent trend of using CBM and PHM strategies.
\end{abstract}

Keywords: Mechanical transmission, condition based maintenance, vibration analysis, health monitoring system, autoregressive.

\section{Introduction}

Monitoring the condition of the in-service mechanical transmission system is an important issue for reliability, where their components deteriorate over the time and affected much when subjected to varying loads. This is led in continues improve of maintenance strategies from breakdown and periodic maintenance to CBM and predictive maintenance in order to sustain reliability and reducing the periodic maintenance costs. Also, in some applications there is more demanding aspect such as saving man's life other than reliability [1]. Smith [2], has defined the causes of transmission vibration and its transmission path, including factors such as manufacturing error, design error and gear tooth deflection, which combine to introduce a transmission error (TE), which is the primary source of the vibration.

\footnotetext{
helmymohamed76@yahoo.com

exp.methods@gmail.com

wessam.hussein@yahoo.com

aelsherif@yahoo.com

Egyptian Armed Forces, Egypt.
} 
Over the past decade, vibration analysis proved to be a trustworthy diagnostic technique that can provide reliable information. However, in the last 10 years researchers devoted a much effort to support CBM actions using vibration information [3-13]. The work focused on the development of reliable features using a suitable signal processing techniques can be grouped in two groups; time domain vibration features including: statistical parameters, time synchronous averaging based methods, filter based methods, stochastic methods and other model based methods. The second group is the frequency domain and time frequency domain features including: first order; (FFT), correlation of spectrum, signal averaging, short time Fourier transform (STFT), continuous wavelet transform (CWT), discrete wavelet transform (DWT), discrete wavelet packet analysis (DWPA), time-averaged wavelet spectrum (TAWS) and time-frequency scale domain (TFS). Second order; power spectrum, Power cepstrum (logarithm of Power spectrum), cyclostationarity, spectrogram Wigner distribution and scalogram. Third order; Bicoherence spectrum, bilinearity and Wigner bi Spectra. Fourth order; Wigner tri Spectra [29].

The authors of this paper continued their research by developing multi sensors fusion algorithms to fuse vibration analysis information with other sensory data, such as acoustic emission and oil debris analysis to minimise false alarms that may occur in failure prediction [14-17]. Also, other researchers devoted efforts to build intelligent algorithms based on vibration features including Expert systems, ANN's, Genetic algorithm, and fuzzy logic [18 28]. Intelligent health monitoring systems incorporate AI algorithms, where AI can be defined as "the science of making machines do things that would require intelligence if done by humans" [33]. To develop an IHMS, the running system condition must be recognized and classified. Researchers have devoted considerable effort to the application of various different soft computing methods to develop IHMSs, and have shown that this can be achieved using methods such as neural networks, fuzzy logic and mathematical modelling based on parametric approaches. All of these methods can provide important tools in the field of intelligent systems which can learn, adapt, and make decisions concerning the system they are in charge of [33].

Artificial neural networks (ANNs) have been used with different HMS techniques such as vibration and acoustic monitoring. An ANN requires input data of the healthy and faulty conditions to be pre-processed, and then these features are used to model the system's behaviour. Fenton et al [36] mentioned that there are two main basic network architectures: feed-forward and recurrent ANNs. Feed-forward ANNs do not have feedback between layers, and previous inputs are not remembered, whereas recurrent ANNs involve feedback between layers and previous inputs are remembered and can be used to reconstruct correlative memory. The two standard neural network architectures used in transmission diagnostics are the feed-forward back propagation network, and the Kohonen feature map which is also known as the self organizing map (SOM) [37]. Fuzzy logic was developed by Zadeh in the 1960s to characterize types of knowledge that cannot be represented by classical Boolean algebra to cover approximate knowledge in describing the behaviour of systems which are difficult to describe mathematically [33].

Currently, the authors of this paper is devoting their efforts in developing smart CBM systems that can use one analysis technique only such as vibration or acoustic emission analysis along with intelligent algorithms to predict the onset of failures; this is to reduce costs of different sensory requirements [30-32]. This paper builds on the author's previous work to develop an online wireless vibration analysis tool for testing automotive mechanical transmissions. The online operation of this system can lead to the wide spread of using such systems with other rotating machinery. 
Parametric methods based on mathematical modelling is to fit measured time series waveform data to a parametric time series model, and then extract features based on this model [34]. Two models are currently in use: the auto regressive (AR) and auto-regressive moving average (ARMA) models. The advantage of mathematical modelling based on parametric methods over the neural networks model-based method is its ability to deal with time series data directly without the need for a signal pre-processing step to extract useful features that can be modelled to represent the system [14]. However, they can only be used to model a time series signal such as a vibration signal, and cannot be applied to combined information from several techniques (vibration, AE and ODA) such as in the case of fuzzy logic.

\section{Design and Implementation of a Testing System for Automotive Mechanical Transmissions:}

An automotive mechanical transmissions gear test rig is currently being developed for this ongoing research. The rig comprises $130 \mathrm{~mm}$ centre distance gearbox. Table1 provides the basic geometry specification for the gears. The system is driven by a $7.5 \mathrm{Kw}$ variable speed electric motor controlled by an inverter to provide a speed variation of $1750 \mathrm{rpm}$. The load is applied via a mechanical breaking mechanism.

Table 1. Gears basic geometry

\begin{tabular}{|c|c|c|c|c|c|c|c|c|c|c|}
\hline \multirow{3}{*}{ Specifications } & \multicolumn{10}{|c|}{ Gear number } \\
\hline & \multicolumn{2}{|c|}{1} & \multicolumn{2}{|c|}{2} & \multicolumn{2}{|c|}{3} & \multicolumn{2}{|c|}{4} & \multicolumn{2}{|c|}{5} \\
\hline & $\mathrm{P}$ & $\mathrm{W}$ & $\mathrm{P}$ & $\mathrm{W}$ & $\mathrm{P}$ & $\mathrm{W}$ & $\mathrm{P}$ & $\mathrm{W}$ & $\mathrm{P}$ & $\mathrm{W}$ \\
\hline Module (mm) & 9.5 & 9.5 & 9.5 & 9.5 & 8 & 8 & 8 & 8 & 8 & 8 \\
\hline Gear Type (H-S) & $S$ & S & $\mathrm{H}$ & $\mathrm{H}$ & $\mathrm{H}$ & $\mathrm{H}$ & $\mathrm{H}$ & $\mathrm{H}$ & $\mathrm{H}$ & $\mathrm{H}$ \\
\hline Number of teeth & 21 & 40 & 19 & 35 & 30 & 33 & 38 & 25 & 43 & 20 \\
\hline $\begin{array}{c}\text { Face Width } \\
(\mathrm{mm})\end{array}$ & 25 & 25 & 25 & 25 & 25 & 25 & 25 & 25 & 30 & 30 \\
\hline Gear Ratio & \multicolumn{2}{|c|}{4.095} & \multicolumn{2}{|c|}{3.96} & \multicolumn{2}{|c|}{2.365} & \multicolumn{2}{|c|}{1.414} & \multicolumn{2}{|c|}{1} \\
\hline
\end{tabular}

The rig can generate a load torque on the test gears in the range of $0-200 \mathrm{Nm}$. The torque is measured using calibrated strain gauges installed on the shaft and the measured torque values are transmitted to the control program by telemetry in order to provide torque control of the loading mechanism on the mechanical transmissions. The test rig is shown in Figure 1. The testing system has been developed for this research work, and is capable of on-line monitoring, automatic measurement, and analysis. Also, any changes in the gears and bearing conditions due to degradation during the operation can be identified. The advantage of developing the system arises from its ability to enhance online analysis methods for vibration technique to provide robust information about the system's condition.

Two temperatures were measured: gearbox oil temperature and bearing temperature using RTD temperature sensors $(10 \mathrm{mv} / \mathrm{C})$. The input shaft speed and motor current were also monitored as a precaution. The test rig operating conditions were monitored and it is flexibly changed according to the required test conditions using LabVIEW's virtual instrument scalable architecture features. 


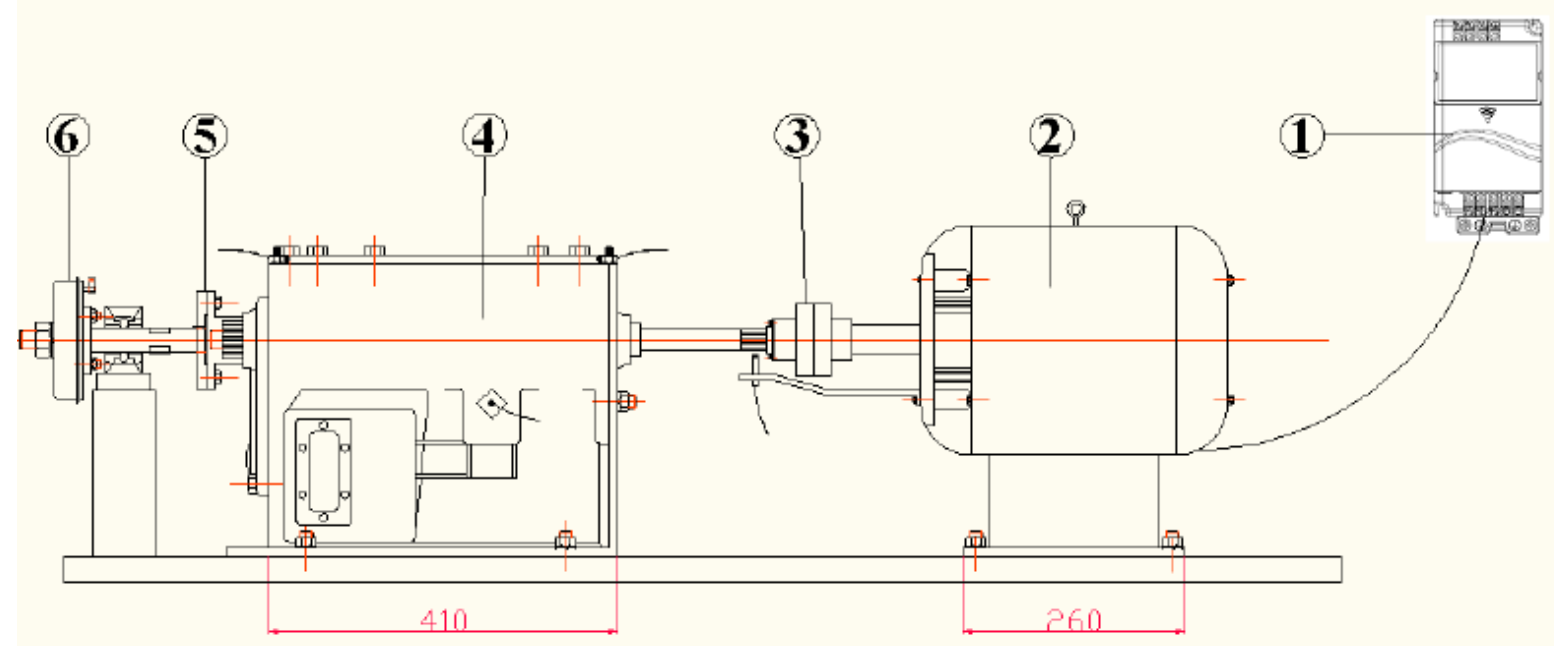

1. Inverter, 2. Electric motor, 3. Fixable coupling, 4. $130 \mathrm{~mm}$ centre distance Gearbox, 5. Mechanical coupling, 6. Loading Mechanism
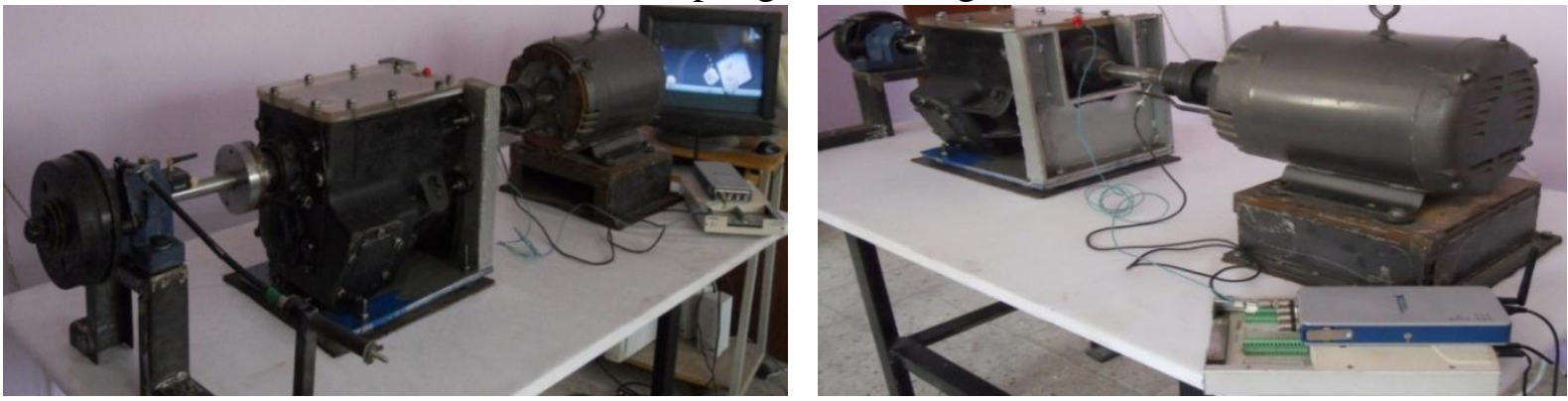

Fig.1. Test rig layout

The Vibration analysis system incorporated a 24-bit NI wireless DSA data acquisition card (NI 9234 with cDAQ-9191) to acquire the vibration signal, speed and temperature. The vibration signals were acquired using two DJB Piezotronic constant current source accelerometers (model no. Acc103-10mV/g) mounted adjacent to the tested gear bearings transversely to the gearbox casing, and a shaft speed sensor was used to acquire the shaft rotation reference. The sensors location diagram over the test rig is shown in Figure 2.

The vibration signals are then acquired continuously and transmitted to the base unit using an IEEE $802.11 \mathrm{~b} / \mathrm{g}$ (Wi-Fi) wireless communication interface (frequency range 2.412-2.462 $\mathrm{GHz}$ ). The system can send the data from a range up to $30 \mathrm{~m}$ for indoor measurements and $100 \mathrm{~m}$ for outdoor operation as long as the line of sight of the wireless signal is provided. The system can also provide Ethernet cabling measurements up to a distance of $100 \mathrm{~m}$. The test rig sensor-actuation system layout is shown in Figure 3.

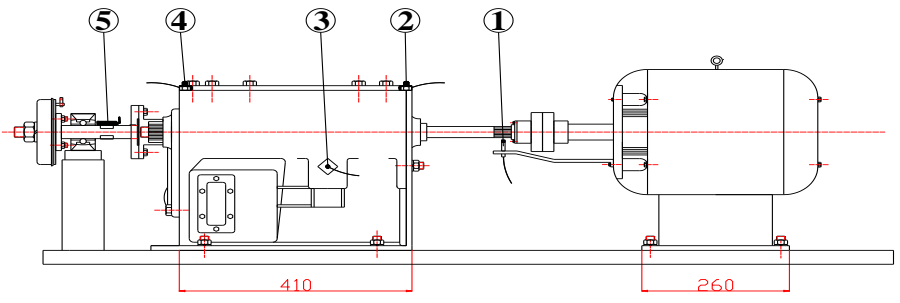

1. Speed sensor

2. Accelerometer 1

3. Temperature sensor

4. Accelerometer 2

5. Torque sensor

Fig.2. Sensors location layout 


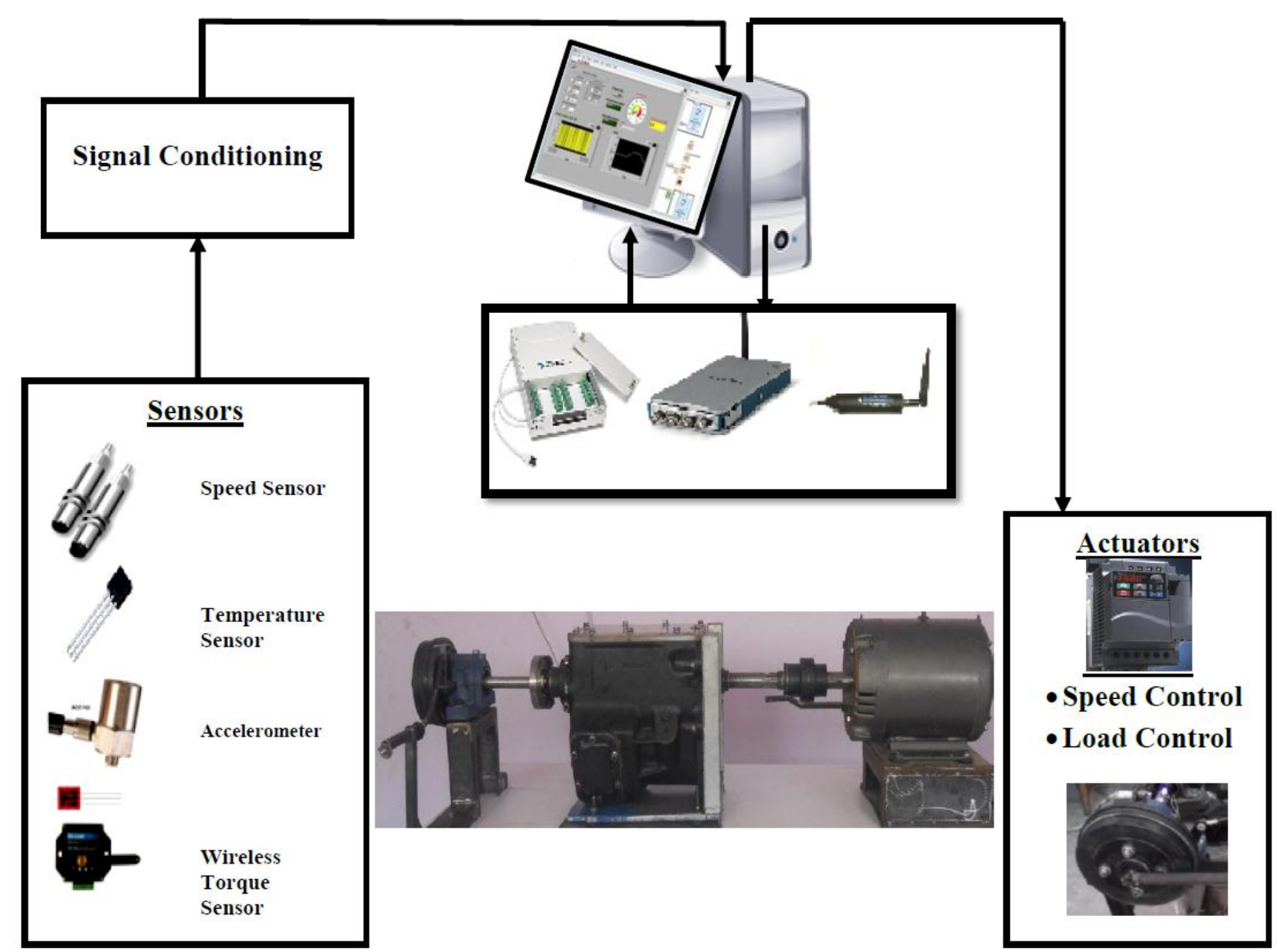

Fig. 3 The test rig sensors - actuation system layout

\section{Design and Implementation of Smart Vibration Analysis Software for Automotive Mechanical Transmissions Testing:}

The reduced set of vector parameters of these models are used to describe the system data required. The method is based on matching the model to a specific data type, such as data from a healthy transmission, and any change in the signal characteristics due to failure will change the statistical properties of the output [35]. Samuel and Pines [34] discussed the differences between various types of parametric method, explaining the AR and ARMA models as follows.

The AR model for a time series $\mathrm{X}$ can be represented by a linear regression of $\mathrm{X}$ on itself plus an error series which is assumed to be noise having a Gaussian distribution. The AR model is given in Equation (1).

$$
x_{i}=-\sum_{\mathrm{k}=1}^{\mathrm{p}} a_{k} x_{i-k}+e_{i}
$$

where $p$ is the model order and provides the number of past inputs required to model the signal, which is determined experimentally, $a_{k}$ are the AR coefficients, $i$ is the sample index, and $e_{i}$ is the Gaussian error series [34].

The ARMA model is a generalized form of the AR model that can represent a time series $X$. The ARMA model is given by Equation (2). 


$$
x_{i}=-\sum_{k=1}^{p} a_{k} x_{i-k}+\sum_{k=0}^{q} b_{k} e_{i-k}
$$

where $p$ and $q$ are the ARMA model order, $a_{k}$ are the AR coefficients, $b_{k}$ are the MA coefficients, $i$ is the sample index, and $e_{i \_k}$ is the model error series. The MA coefficients $b_{k}$ have to be computed after the AR coefficients are determined, hence the AR approach has a computational advantage over the ARMA approach [34].

The smart vibration analysis system software is developed in the NI LabVIEW environment to provide continuous online system monitoring using vibration features, including the real time mode and transient analysis. Blocks of 12600 discrete samples were continuously received at the base unit and analysed, these features were then processed using several algorithms and logged continuously in order to build up the data history. All the analysis, feature extraction, and data logging processes of the vibration features are achieved at the base unit. The validation of the developed monitoring algorithm based on AR approach was successful on small scale mechanical transmissions [30].

\section{Testing and Validation of the Automotive Mechanical Transmissions Test Rig and the Smart Vibration Analysis Software}

The system validation will comprise a series of tests designed to achieve the proposed aim of developing and validating the behaviour of the smart vibration analysis software including the AR algorithms, and investigating its capability to provide information to users about the system status. All tests were undertaken in such a way as to ensure that failures would develop.

Further publications will follow to provide the results of this series of tests including, for healthy, in-service, and faulty gears that are working in real application such as automotive transmission gear box in which the failure under accelerated conditions were brought about by introducing artificial errors to the gear flanks. All the three testes will be carried out at the same speed and torque until the tests end.

\section{Conclusions}

The study has presented a new wireless vibration measuring system that was able to detect different conditions of gears in automotive gearbox and clearly identify its condition using only one accelerometer placed on the gearbox casing. The study has focused on monitoring the progression of gear faults in spur and helical gears, using model-based parametric method AR algorithms based on vibration data only. The online information about the transmission condition can provide a solution for PHM systems. The system solved a major problem for application those sensing points are far from acquisition and analysis point. The system is being developed for use on $130 \mathrm{~mm}$ automotive manual transmissions, but could be adapted for other transmission or machinery systems rotating machinery. Further publications will follow to provide the results of the vibration analysis tool including the AR algorithms.

\section{References}

[1] Scheffer, C. and Girdhar, P. (2004) Machinery Vibration Analysis and Predictive Maintenance, Newnes Press; ISBN 0750662751.

[2] SMITH, J.D. (1983) Gears and Their Vibration: A Basic Approach to Understanding Gear Noise, New York: M. Dekker; London: Macmillan Press. 
[3] ONSY, A., SHAW, B.A. \& JISHAN, Z. (2011) Monitoring the Progression of Micro-Pitting In Spur Geared Transmission Systems Using Online Health Monitoring Techniques. SAE International Journal of Aerospace. November 20114:1301-1315.

[4] ONSY, A., BICKER, R., SHAW, B.A., ROWLAND, C.W. \& KENT, T. (2008b) Monitoring Bending Fatigue Failure in Helical Gears Using Acoustic Emission, Vibration, and On-Line Oil Debris Analysis: A Comparative Study. Proceedings of the Fifth International Conference on Condition Monitoring \& Machinery Failure Prevention Technologies, UK, Edinburgh.

[5] TAN, C.K., IRVING, P. \& MBA, D. (2005) Diagnostics and Prognostics with Acoustic Emission, Vibration and Spectrometric Oil Analysis For Spur Gears: A Comparative Study. Insight: Non-Destructive Testing and Condition Monitoring, 47, 478-480.

[6] AL-GHAMD, A.M. \& MBA, D. (2006) A Comparative Experimental Study on the Use of Acoustic Emission and Vibration Analysis for Bearing Defect Identification and Estimation of Defect Size. Mechanical Systems and Signal Processing, 20, 1537-1571.

[7] G. Dalpiaz, A. Rivola and R. Rubini, (2000) Gear Fault Monitoring: Comparison of Vibration Analysis Techniques, Department of Mechanical Design Engineering University of Bologna, Italy.

[8] C. James Li, J.D. Limmer, (2000) Model-based condition index for tracking gear wear and Fatigue damage, Wear 241 _2000. 26-32, Department of Mechanical Engineering, Aeronautical Engineering and Mechanics, Rensselaer Polytechnic Institute, Troy, USA.

[9] Enayet B. Halim, Sirish L.Shah, Mingo j.Zuo and A. A. Shoukat Choudhury, (2004) Fault Detection of Gearbox from Vibration Signals using Time-Frequency Domain Averaging.

[10] Johan Wandell, (2006) Multistage Gearboxes: Vibration Based Quality Control, TRITA-AVE 2006:27 ISSN 1651-7660, Royal Institute of Technology School of Engineering Sciences Department of Aeronautical and Vehicle Engineering the Marcus Wallenberg Laboratory for Sound and Vibration Research.

[11] P.Gupta, S. B. Wadkar, (2008) Comparative Vibration and Noise Signature Analysis by Spectral, Cepstral and Wavelet Techniques, P.Gupta and S. B. Wadkar/ Advances in Vibration Engineering, 7(2) 2008 Department of Mechanical Engineering, College of Engineering, Bbartj Vidyapeeth Deemed University, India.

[12] Grzegorz Wojnar, Bogusław Lazara, Henryk Madej, (2008) Diagnostics of Power Transmissions System with Tooth Gear, Silesian University of Technology, Faculty of Transport, Department of Automotive Vehicle Construction, Poland.

[13] Matej Gasperin, ani Juricic, Pavle Boskoski, Joz ef Vizintin, (2011) Model-based Prognostics of Gear Health using stochastic dynamical models, Mechanical Systems and Signal Processing 25(2011) 537-548, Department of Systems and Control, Slovenia

[14] ONSY, A., BICKER, R. \& SHAW, B.A. (2010) A Novel Intelligent Health Monitoring System for Gear Fatigue Failure Prediction. 23 ${ }^{\text {rd }}$ International Congress on Condition Monitoring and Diagnostic Engineering Management; COMADEM 2010, Japan, Nara, ISBN 978-4-88325-419-4.

[15] ONSY, A., BICKER, R. \& SHAW, B.A. (2010) Intelligent Diagnostic Health Management of Power Transmission Systems: An Experimental Validation, International Journalof COMADEM 2010, 13(2), 46-58. 
[16] ONSY, A., BICKER, R., SHAW, B.A., ROWLAND, C.W. \& KENT, T. (2009) Intelligent Health Monitoring Of Power Transmission Systems: An Experimental Validation. Proceedings of the 2009 Conference of the Society for Machinery Failure Prevention Technology, USA, Dayton, Ohio, 499-518.

[17] ONSY, A., BICKER, R., SHAW, B.A., ROWLAND, C.W. \& KENT, T. (2008a) Monitoring the Progression of Micro-Pitting in Helical Gears: Towards an Intelligent Health Monitoring System. Paper presented at the $A E W G-51$ \& International Symposium on AE, USA, Memphis, Tennessee.

[18] Paula J. Dempsey, Abdollah A. Afjeh, (2002) Integrating Oil Debris and Vibration Gear Damage Detection Technologies Using Fuzzy Logic, NASA/TM-2002211126, National Aeronautics and Space Administration Glenn Research Center, USA.

[19] Abhinav Saxena, Ashraf Saad, PhD, (2005) Evolving an Artificial Neural Network Classifier For Condition Monitoring of Rotating Mechanical Systems, Journal of Applied Soft Computing Elsevier Publishers, ISSN: 1568-4946, School of Electrical and Computer Engineering, Georgia Institute of Technology, Savannah, a 31407, USA.

[20] T.HLoutas, J.Kalaitzoglou, G.Sotiriades, V.Kostopoulos, (2005) the Combined Use of Vibration, Acoustic Emission and Oil Debris Sensor Monitored Data Coming from Rotating Machinery for the Development of a Robust Health Monitoring System, Department of Mechanical Engineering and Aeronautics, University of Patras, Patras.

[21] M.H. Sadeghi, J. Raflee, F. Arvani, and A. Harifi, (2006) A Fault Detection and Identification System for Gearboxes using Neural Networks, Center of Excellence for Mechatronics, University of Tabriz, Tabriz, Iran.

[22] J. Rafiee, F. Arvani, A. Harifi, M.H. Sadeghi, (2007) intelligent condition monitoring of a Gearbox using artificial neural network, Mechanical Systems and Signal Processing 21 (2007) 1746-1754, Department of Mechanical Engineering, University of Tabriz,Tabriz, Iran.

[23] S.J. Loutridis, (2008) Gear failure prediction using multiscale local statistics, Engineering Structures 30 (2008) 1214-1223, Technological Educational Institute of Larissa, School of Technological Applications, Department of Electrical Engineering, Sensors an Instrumentation Laboratory, GR 41-110 Larissa, Greece.

[24] T.H. Loutas, G. Sotiriades, I. Kalaitzoglou, V. Kostopoulos, (2009) Condition monitoring of A Single Stage gearbox with artificially induced gear cracks utilizing on-line vibration and Acoustic Emission measurements, Applied Acoustics 70(2009)1148-1159, Department of Mechanical Engineering and Aeronautics, University of Patras, Patras GR-26500, Greece.

[25] N. Saravanan, S. Cholairajan, K.I. Ramachandran, (2009) Vibration-based fault diagnosis of Spur Bevel gear box using fuzzy technique, Expert Systems with Applications 36 (2009) 3119-3135, Department of Mechanical Engineering, Amrita Vishwa Vidyapeetham, Coimbatore, Tamil Nadu 641105, India.

[26] J. Rafiee, P.W.Tse, (2009) Use of autocorrelation of wavelet coefficients for fault diagnosis, Mechanical Systems and Signal Processing 23 (2009) 1554-1572, Department of Mechanical, Aerospace and Nuclear Engineering, Jonsson Engineering Center, Troy, USA.

[27] J. Rafiee , M.A. Rafiee, N. Prause , P.W. Tse, (2010) Application of Daubechies 44 in Machine Fault Diagnostics, Dept. of Mechanical, Aerospace \& Nuclear Engineering, Rensselaer Polytechnic Institute, NY, USA 
[28] Piotr Czech, .Boguslaw Lazar, Henryk Madej, Grzegorz Wojnar, (2010) Classification Of Tooth Gear Wheel Faults of Gearbox Working In the Circulating Power Test Rig By Multilayer Perceptron and Continuous Wavelet Transform, ACTA Technica Corviniensis - Bulletin of Engineering ISSN: 2067-3809, Faculty of Transport, Silesian University of Technology, Gliwice, POLAND.

[29] Hongyu Yang, Joseph Mathew and Lin Ma, (2003) Vibration Feature Extraction Techniques For Fault Diagnosis of Rotating Machinery-A Literature Survey, AsiaPacific Vibration Conference, 12-14 November 2003, Gold Coast, Australia, School of Mechanical Manufacturing and Medical Engineering, Australia.

[30] ONSY, A., BICKER, R. \& SHAW, B.A. (2013) Predictive Health Monitoring of Gear Surface Fatigue Failure Using Model-based Parametric Method Algorithms; An Experimental Validation. SAE International Journal of Aerospace. September 2013 Issue.

[31] ABELAZEZ, W.,ONSY, A.\& SHERIF, I. (2013) (in press) Health Monitoring of Electro-Pneumatic Controlled Systems using Multivariate Latent Methods: An Experimental Validation, SAE International Journal of Materials and Manufacturing 2013 Issue.

[32] ONSY, A., BICKER, R., SHAW, B. A. \& FOUAD, M. (2012) Application of Image Registration Techniques in Monitoring the Progression of Surface Fatigue Failures in Geared Transmission Systems.The AeroConf 2012 IEEE Aerospace Conference, USA, Big Sky.

[33] JAIN, L. C. \& SILVA, C. W. (1999) Intelligent Adaptive Control, Industrial Applications.

[34] SAMUEL, P.D. \& PINES, D. J. (2005) A Review of Vibration-Based Techniques for Helicopter Transmission Diagnostics. Journal of Sound and Vibration, 282, 475508.

[35] BRAUN, S. (1986) Mechanical Signature Analysis - Theory and applications. London: Academic Press Inc.

[36] Fenton, W.G., McGinnity, T.M., \& Maguire, L.P. (2001) Fault Diagnosis Of Electronic Systems Using Intelligent Techniques: A Review. IEEE Transactions on Systems, Man and Cybernetics Part C: Applications and Reviews, 31, 269-281.

[37] Jardine, A.K.S., Lin, B., \& Banjevic, D. (2006) A Review On Machinery Diagnostics And Prognostics Implementing Condition-Based Maintenance, Mechanical Systems and Signal Processing, 20, 1483-1510. 